\title{
Investigate Chemical Effects of Pre-Chamber Combustion Products on Main Chamber Ignition Performance under an Ultra-Lean Condition
}

\author{
Wenxian Tang and Mani Sarathy King Abdullah University of Science \& Technology
}

Citation: Tang, W. and Sarathy, M., "Investigate Chemical Effects of Pre-Chamber Combustion Products on Main Chamber Ignition Performance under an Ultra-Lean Condition,” SAE Technical Paper 2020-01-2001, 2020, doi:10.4271/2020-01-2001.

\section{Abstract}<smiles>c1ccccc1</smiles>
re-chamber ignition systems are considered as an effective technique to achieve an ultra-lean burn combustion. Hot combustion products and flames generated from pre-chamber combustion create high-speed turbulent jets, which ignite an ultra-lean mixture in the main chamber. This turbulent ignition can be classified as a jet and flame ignition process with thermal and chemical kinetic effects imposed on the main chamber by the pre-chamber. The purpose of this paper is to investigate the chemical effects of pre-chamber combustion products on main chamber ignition performance over a range of operating conditions in prechamber. A zero-dimensional pre-chamber combustion model was developed using CHEMKIN-PRO software. By varying the equivalence ratio of reactants, simulation results indicated that the pre-chamber generated more active radicals when burning around stoichiometric conditions but more low-carbon species when burning in rich conditions. Therefore, rapid ignition performance was observed in the ultra-lean mixture of main chamber with additional combustion products from the pre-chamber burning with a stoichiometric mixture. This contributed to the transfer of highly active species especially $\mathrm{OH}$ radicals from pre-chamber into main chamber. Heat release rate and laminar flame speed are promoted with combustion products from pre-chamber burning with a relatively rich mixture. The related reaction and species sensitivity analysis were also conducted to explain the above findings.

\section{Introduction}

W ith the increasingly serious climate and atmospheric changes, stringent regulations and related studies have been prompted to minimize environmental impacts. The transport sector is one of the largest greenhouse gases emitters and the current research interest is emphasized in achieving a more efficient and cleaner combustion in internal combustion engines, which presents to be a potential path to reduce specific fuel consumption and exhaust emissions regardless of engine geometric modifications [1]. However, in addition to the benefits, the major challenge in lean burn combustion is to ignite the lean mixture at the start of combustion [2]. Therefore, lean burn ignition systems have been widely studied and the pre-chamber (PC) combustion system is being considered as one of promising concepts to obtain the lean burn combustion.

The PC combustion system is usually characterized by two parts of pre-chamber and main chamber. A small prechamber is located in the head with a rich mixture and main chamber is inside the cylinder containing a lean mixture. The application of PC combustion systems has been verified to be effective for improving ignition performance in lean burn combustion, and a range of studies have been conducted in investigating the influences of pre-chamber systems on main chamber combustion characteristics.

For the start of combustion, Toulson et al. []ㅡ evaluated the combustion performance of a hydrogen assisted jet ignition system in a cooperative fuel research engine with gasoline mixture in main chamber and various gaseous fuels in pre-chamber. The experimental results found that when using liquefied petroleum gas, compressed natural gas, carbon monoxide $(\mathrm{CO})$ and hydrogen $\left(\mathrm{H}_{2}\right)$ in the pre-chamber respectively, $\mathrm{H}_{2}$ produced the fastest ignition in the main chamber. Moreover, the flame initiation did not increase substantially with an increasing air/fuel equivalence ratio in the main chamber. This indicated that the improvement of ignition levels in main chamber mainly depends on flame propagation and chemically active combustion products generated from pre-chamber, rather than the energy density of fuel. Attard et al. [4] compared ignition and combustion characteristics in an optical single cylinder engine with and without a stratified turbulent jet ignition (TJI) system, using natural gas fueled in the main chamber. It was found that the employment of a TJI system produced a brighter and more intense blue flame than in the conventional engine, consequently faster ignition and more stable combustion. The authors explained that these effects were due to the jets and highly active species from pre-chamber injected into the distributed ignition sites in main chamber. Gentz et al. [5] tested the initial combustion stage $(0-10 \% \mathrm{MFB})$ of a baseline spark ignition (SI) engine with and without TJI systems in a Rapid Compression Machine (RCM). It was observed that the propagation of burned fraction was slower than almost all TJI tested cases, 
which concluded that the TJI system promoted combustion initiation in the SI engine.

Besides the start of combustion, heat release rate is also analyzed as an important parameter on combustion process study of PC ignition systems. Sakai et al. [] conducted experiments for a single cylinder engine with and without a prechamber system. For the engine with pre-chamber system, a quick increase in heat release rate at the initial stage of combustion was observed followed by a decrease after a short stable period. Moreover, this study pointed out that the first peak of heat release rate in main chamber was affected by air/ fuel equivalence ratio inside the pre-chamber. For a rich mixture in the pre-chamber, the initial heat release rate increased rapidly and decreased steadily afterward. However, the peak value of heat release rate gradually decreased with a leaner mixture in pre-chamber, getting close to that of the original engine.

In addition to the start of combustion and heat release rate, flame propagation speed is also a vital part in studying the burning process of pre-chamber combustion systems. Gentz et al. [5] also examined the major combustion duration (10-90\% MFB) for the conventional engine and three with PC system applications. It was found that burn duration from 10 to $90 \%$ was faster with the use of PC ignition systems than the original engine, indicating that flame propagation speed was improved. As Gentz et al. [ㅁ, ]] Attard et al. [4] also showed an agreement that the application of PC system shortened the burn duration of $10-90 \%$ MFB. This suggested that multiple flames propagate in main chamber, which was attributed to the enhanced combustion provided by pre-chamber jets with high levels of active species.

Many studies $[1, \underline{3}, \underline{4}, \underline{5}, \underline{6}, \underline{7}, \underline{8}, \underline{9}, \underline{10}, \underline{11}]$ have reported that the application of pre-chamber systems produces an increase in turbulence, available energy and active chemical species at the start of combustion, consequently improving the combustion performance in the main chamber. However, the chemical effects of pre-chamber combustion species on the ignition performance of main chamber have not been studied extensively. Therefore, this paper is interested in establishing a numerical zero-dimensional pre-chamber combustion model with the software of CHEMKIN-PRO and investigating the chemical effects of combustion species injected from prechamber on the ignition performance, heat release rate and laminar flame speed in the main chamber. Related species and reactions sensitivity analyses are also conducted and discussed.

\section{Methodology}

\section{Pre-Chamber Combustion System Modeling}

The working principle of the PC combustion system is that hot combustion products and flame issued from pre-chamber forms a high speed turbulent jet that ignites a lean mixture in the main chamber [12]. Therefore, to develop a general understanding of the chemical effects of the pre-chamber combustion products on ignition performance of an ultra-lean mixture in main chamber, the pre-chamber combustion system is simplified to be two independent zero-dimensional combustion zones in modeling, which are referred as prechamber and main chamber respectively. For the fuel selection, PC combustion systems are potentially suitable for high octane fuel combustion since they are able to obtain lean burn combustion, and then achieve better knock control due to the increased turbulence and energy inside the main chamber $[13,14]$. Hence iso-octane, as one of important components of the gasoline surrogate fuel and a typical high octanenumber fuel, is used in both pre- and main chambers. To study the chemical effects of pre-chamber combustion on the main chamber ignition behavior, the pre-chamber is operated for a range of equivalence ratios and the main chamber is fueled with an ultra-lean mixture with the equivalence ratio of 0.4 . To connect the two isolated combustion zones, combustion products obtained from pre-chamber simulations are added into main chamber as part of reactants considering the partial mixing model wherein the pre-chamber species are mixed with $50 \%$ of the main chamber volume gases. This model considers the actual ignition situation that combustion products injected from pre-chamber are initially mixed with a lean mixture near the top area in main chamber, followed by the local ignition, and then the whole chamber is burned through the flame propagation and piston movement. Besides the chemical effects, flame and heat generated from prechamber burning are transformed directly to be an increase in initial temperature and pressure at the start of combustion in the main chamber for a range of analysis.

\section{Pre- and Main Chambers Simulating}

For simulations, pre-chamber combustion is computed using a constant-volume batch reactor in CHEMKIN-PRO software for a wide range of equivalence ratios from 1.0 to 5.0. The initial temperature and pressure are set with $1000 \mathrm{~K}$ and 20 bar. KAUST Atef et al. mechanism [15] is applied for isooctane simulations. To develop a general list of main species from pre-chamber for various operating conditions, there are 3 groups of combustion species taken into considerations: major combustion products and unburned air molecules such as water $\left(\mathrm{H}_{2} \mathrm{O}\right)$, $\mathrm{CO}$, carbon dioxide $\left(\mathrm{CO}_{2}\right), \mathrm{H}_{2}$, nitrogen $\left(\mathrm{N}_{2}\right)$, and oxygen $\left(\mathrm{O}_{2}\right)$; radicals with high reactivity such as $\mathrm{H}, \mathrm{OH}$; and some important intermediate species including methyl radical $\left(\mathrm{CH}_{3}\right)$, methane $\left(\mathrm{CH}_{4}\right)$, formaldehyde $\left(\mathrm{CH}_{2} \mathrm{O}\right)$, acetylene $\left(\mathrm{C}_{2} \mathrm{H}_{2}\right)$, ethylene $\left(\mathrm{C}_{2} \mathrm{H}_{4}\right)$, ethyl radical $\left(\mathrm{C}_{2} \mathrm{H}_{5}\right)$, ethane $\left(\mathrm{C}_{2} \mathrm{H}_{6}\right)$, propyne $\left(\mathrm{C}_{3} \mathrm{H}_{4}\right)$, propene $\left(\mathrm{C}_{3} \mathrm{H}_{6}\right)$, 1-butene-3-yne $\left(\mathrm{C}_{4} \mathrm{H}_{4}\right)$, 2-butyne $\left(\mathrm{C}_{4} \mathrm{H}_{6}\right)$ and benzene $\left(\mathrm{C}_{6} \mathrm{H}_{6}\right)$. Besides identifying main components of pre-chamber combustion products, the hard spot is to determine the concentrations of these species accurately. In regards to this, for a qualitative and quantitative analysis, combustion products transported from pre-chamber are ideally considered in two extreme situations concerning the maximum and minimum chemical effects. Combustion products with maximum active species, which assumes that the pre-chamber is partially burned and produces the highest concentrations of active radicals $\mathrm{H}$ and $\mathrm{OH}$. This is obtained at the time of peak $\mathrm{H}$ or $\mathrm{OH}$ 
TABLE 1 Detailed simulating condition for pre- and main chamber combustion.

\begin{tabular}{|c|c|c|c|c|c|c|c|}
\hline PC system & Fuel & Technique & Reactor & Temperature/K & $\begin{array}{l}\text { Pressure/ } \\
\text { bar }\end{array}$ & $\begin{array}{l}\text { Equivalence } \\
\text { ratio }\end{array}$ & Mechanism \\
\hline Pre-chamber & iso-octane & Oxidation & \multirow{2}{*}{$\begin{array}{l}\text { Constant-volume } \\
\text { reactor }\end{array}$} & 1000 & 24 & $1-5$ & \multirow[t]{2}{*}{ Atef model [15] } \\
\hline \multirow[t]{2}{*}{ Main chamber } & \multirow[t]{2}{*}{ iso-octane } & $\begin{array}{l}\text { Ignition delay/Heat } \\
\text { release rate }\end{array}$ & & $800-1500$ & $30-60$ & \multirow[t]{2}{*}{0.4} & \\
\hline & & Laminar flame speed & $\begin{array}{l}\text { Premixed laminar } \\
\text { flame speed } \\
\text { simulator }\end{array}$ & 900 & 20 & & $\begin{array}{l}\text { KAUST reduced } \\
\text { TPRFE [16] }\end{array}$ \\
\hline
\end{tabular}

concentrations. Combustion products with minimum active species assumes that the pre-chamber is completely burned and produces less active radicals of $\mathrm{H}$ and $\mathrm{OH}$. The gas composition is obtained at the time of complete combustion of the pre-chamber reactants.

For main chamber simulations, the ignition delay time and heat release rate of an ultra-lean mixture without and with additional combustion products from pre-chamber are also studied and compared with the application of a constantvolume batch reactor. The initial temperature and pressure are set from 800 to $1500 \mathrm{~K}$ and 30 to 60 bar considering a range of thermal effects impacted from the pre-chamber due to different operating conditions. Regarding the laminar flame speed, the simulating temperature and pressure are raised to be $900 \mathrm{~K}$ and 20 bar as greater energy is provided from prechamber at the initiation of combustion in main chamber. The reduced KAUST TPRFE mechanism [16] is employed in computations to reduce the convergence problems. The detailed simulating conditions of pre-chamber and main chamber combustion are summarized in Table 1.

\section{Results and Discussion}

\section{Main Combustion Species from Pre-Chamber into Main Chamber}

Figure 1 compares the concentrations of important combustion species obtained from pre-chamber simulations for various equivalence ratios, concerning two cases of combustion products with maximum and minimum active species. Comparing stable combustion products and remaining oxygen observed from two cases, Figure 1(1-a) displays high concentrations of $\mathrm{H}_{2} \mathrm{O}$ and $\mathrm{CO}$ for all ranges of equivalence ratios and the concentrations of $\mathrm{CO}_{2}$ and $\mathrm{O}_{2}$ are decreased with an increase of the equivalence ratio in pre-chamber. Figure 1(1-b) shows higher concentrations of stable combustion products under the same operating conditions, and significantly high proportions of $\mathrm{CO}$ and $\mathrm{H}_{2}$ species are observed when pre-chamber burning in rich conditions. As active radicals distributions shown in Figure 1(1-b) and (2-b), it is clear that more active radicals are generated when pre-chamber burning under the stoichiometric condition, and there are nearly negligible active radicals produced when pre-chamber burning in an extremely rich condition for both the maximum and minimum active species cases. It is worth noting that more than $1 \%$ of $\mathrm{OH}$ radicals are produced when burning a stoichiometric mixture in prechamber. Figure 1(1-c) and (2-c) describe a consistent tendency that the proportions of intermediate species are gradually increased with an increasing equivalence ratio in pre-chamber due to fuel pyrolysis reactions. Among these species, $\mathrm{CH}_{4}$ demonstrates the greatest growth rate and takes a high proportion of over $7 \%$ when burning with an ultra-rich mixture. To sum up, for a range of equivalence ratios in pre-chamber, more active radicals are produced for a stoichiometric combustion and more low-carbon species are generated for a fuelrich combustion.

\section{Effects of Pre-Chamber Combustion Products on Ignition Delay Time in Main Chamber}

There are various definitions of ignition delay time and in this study, the ignition delay time is determined by the time of maximum temperature rise. Figure 2 depicts the ignition performance in main chamber with the addition of combustion products from pre-chamber considering the maximum active species case, for a range of initial temperature and pressure from 800 to $1500 \mathrm{~K}$ and 30 to 60 bar. From figure 2, it is observed that the ignition performance is improved significantly with the addition of combustion species from pre-chamber burning under the stoichiometric condition and these improvements seem to be more obvious in the low temperature range from 800 to $1000 \mathrm{~K}$. While with the addition of combustion products from pre-chamber burning in rich conditions, there is no enhancement or only slight enhancements observed in the ignition delay time for medium and high temperatures. Comparing figure 2(a) and (b), it can also see that with a higher initial pressure, ignition improvements become more obvious with the addition of combustion products from pre-chamber. Similar results are also found in Figure 3 considering the minimum active species case. These results indicate that adding species from pre-chamber burning under the stoichiometric condition significantly improve the ignition performance, while there is no apparent differences observed between with additional species from pre-chamber burning under rich conditions and without additional species from pre-chamber.

To validate the rapid ignition performance with additional species from pre-chamber burning under stoichiometric conditions, the reactant consumption profiles for low initial temperatures from 800 to $1000 \mathrm{~K}$ are plotted in figure 4. It is observed that iso-octane is consumed rapidly at the initiation of 
FIGURE 1 Main combustion species from pre-chamber combustion for a range of equivalence ratios considering (1) combustion products with maximum active species [(1-a) stable combustion products and extra oxygen, (1-b) active radicals, and (1-c) important intermediate species], (2) combustion products with minimum active species [(2-a) stable combustion products, (2-b) active radicals, and (2-c) important intermediate species].
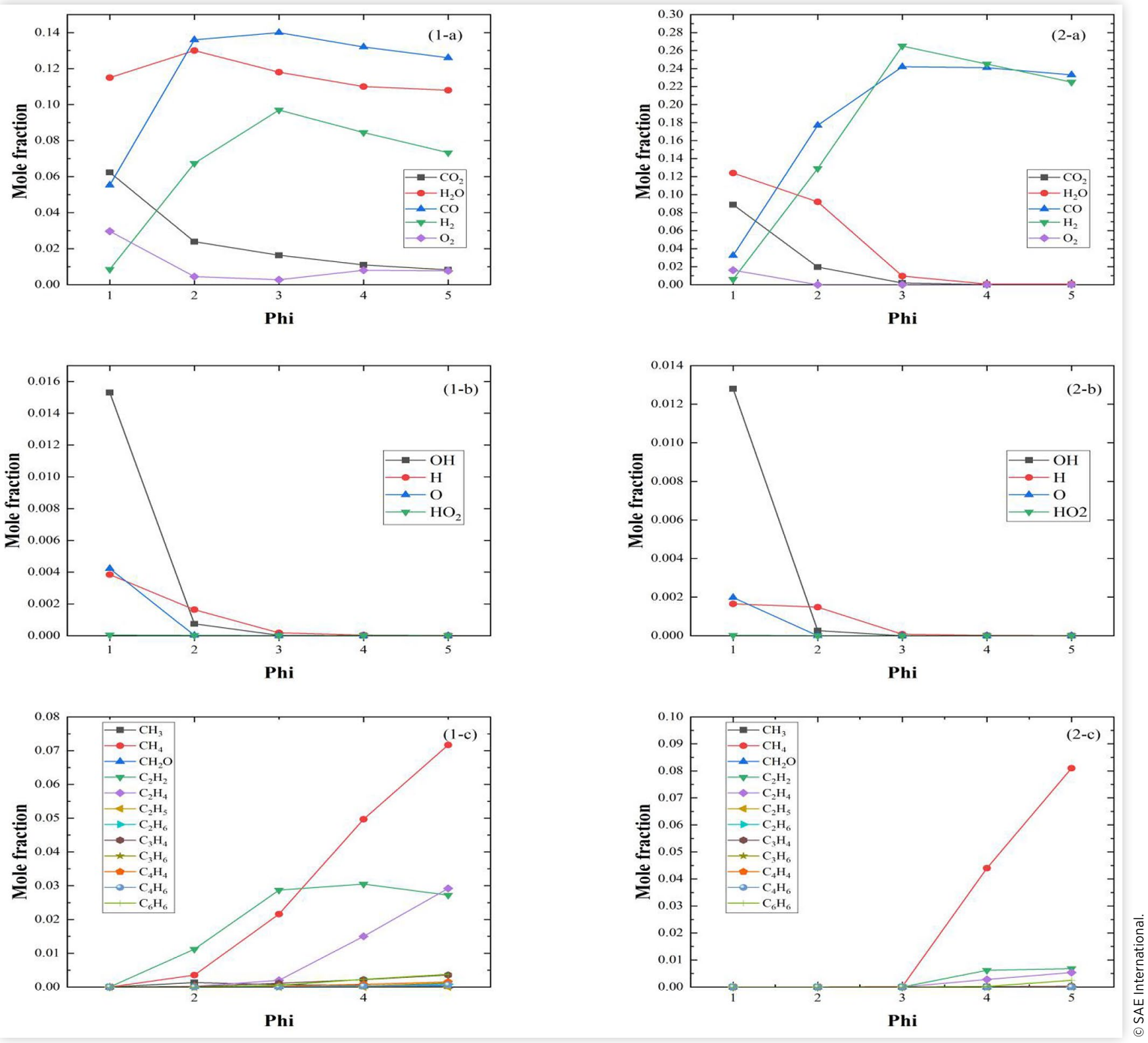

simulations considering both maximum and minimum active species cases. This is consistent with previous results of ultraquick ignition performance, which may be potentially explained by rich active radical-induced ignition behavior $[\underline{17}, \underline{18}]$.

Moreover, additional species sensitivity analysis is conducted to understand how combustion species affect the ignition performance of an ultra-lean mixture in main chamber. When burning with a stoichiometric mixture, the major chemical species transported from pre-chamber into main chamber are active radicals of $\mathrm{H}, \mathrm{OH}$ and $\mathrm{HO} 2$, and molecules of $\mathrm{CO}$ and $\mathrm{H} 2$ with high concentrations. These species are added into main chamber individually for species sensitivity analyses. Figure 5 illustrates the ignition performance with individual species from pre-chamber at the initial pressure of
30 bar. Regarding the case of maximum active species, it can be observed from Figure 5(a) that when adding $\mathrm{OH}$ radical with a concentration of $0.776 \%$, the ignition performance is improved significantly and it shows a similar tendency with Figure 2 and $\underline{3}$, wherein a relatively shorter ignition delay time is predicted in the low temperature range of 800 to $1000 \mathrm{~K}$. Adding $\mathrm{H}$ radical with a concentration of $0.2 \%$ also produces some positive effects in ignition performance refinement. But the degree of refinement seems to be decreased with an increase of initial temperature, and these refinements are nearly negligible for high temperatures of 1400 and $1500 \mathrm{~K}$. For the addition of CO and $\mathrm{H}_{2}$ species with high concentrations, there is no obvious differences observed in the ignition delay time compared to the without additional species case. Figure 5(b) indicates the 
FIGURE 2 Ignition performance in main chamber with additional combustion products from pre-chamber for various equivalence ratios concerning combustion products with maximum active species under the pressure of (a) 30 bar and (b) 60 bar.

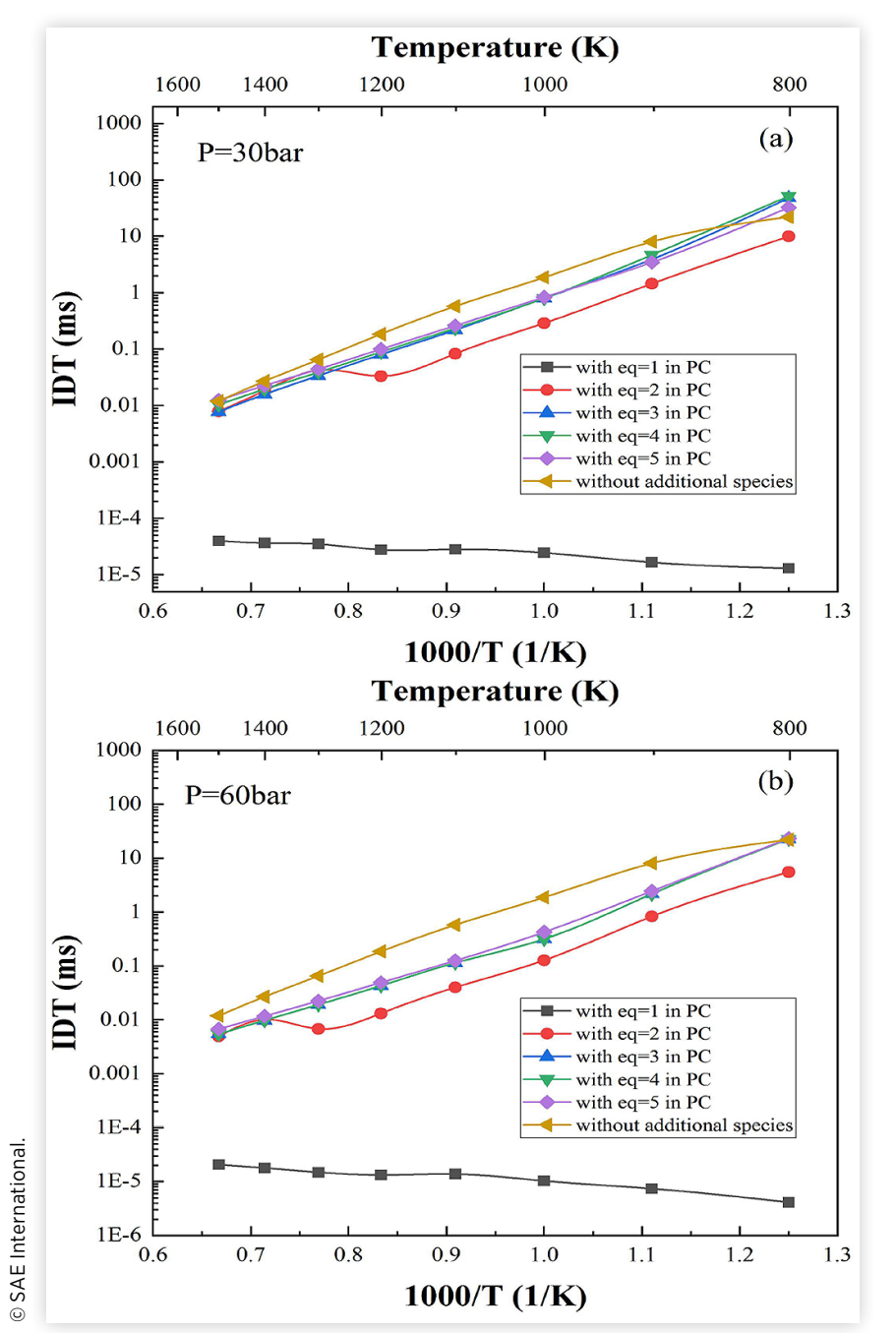

individual species sensitivity analysis regarding the case of minimum active species. It also suggests an overall improvement tendency with the addition of $\mathrm{H}$ and $\mathrm{OH}$ radicals and no promotions with the addition of other species. To further compare two figures, figure 5(a) predicts more obvious improvements due to higher concentrations of active radicals, and it is also found that active species with minor concentrations produce less effects in the ignition performance. Based on the above analysis, the ignition performance improvement in the main chamber is highly advanced due to active radicals species $\mathrm{OH}$ radical injected from the pre-chamber.

\section{Effects of Pre-Chamber Combustion Products on Heat Release Rate in Main Chamber}

Figure 6 describes the heat release profiles in main chamber with the addition of combustion species from pre-chamber
FIGURE 3 Ignition performance in main chamber with additional combustion products from pre-chamber for various equivalence ratios concerning combustion products with minimum active species under the pressure of (a) 30bar and (b) 60 bar.

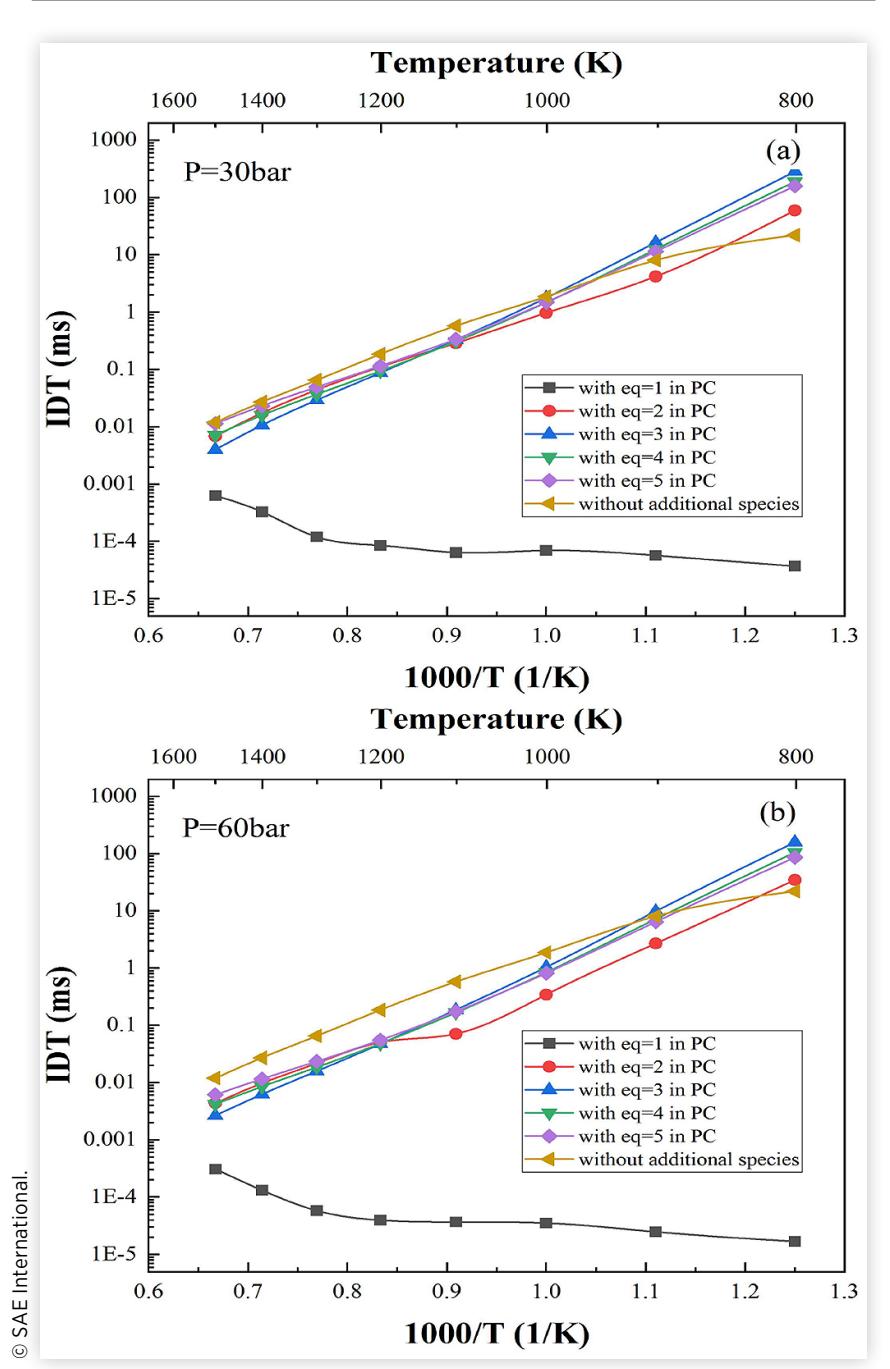

for a range of operating conditions considering the maximum active species case, at the initial temperature and pressure of $1000 \mathrm{~K}$ and 30 bar. From figure 6(a), it is found that all cases of with additional species from pre-chamber show a peak value of heat release rate at the initiation of simulation. And among various equivalence ratios in pre-chamber, the highest peak value of heat release rate is obtained with eq $=1.0$ in pre-chamber. This is potentially explained by the intense active species reactions at the start of combustion in main chamber. Moreover, with the addition of combustion species from pre-chamber burning with rich mixtures, heat release rate drops rapidly after the peak value. While with the addition of combustion species from pre-chamber operating with a stoichiometric mixture, the heat release rate is reduced slowly. This may be attributed to the rapid ignition and hence amount of heat released. Figure 6(b) mainly compares the heat release rate profiles with additional species from pre-chamber burning in rich conditions and without additional species from pre-chamber. It is found that the heat release rate is 
FIGURE 4 Iso-octane concentration changes through the time with additional species from pre-chamber burning with a stoichiometric mixture for low initial temperatures. The solid line and dash line denote the additional species with maximum active species and with minimum active species respectively.

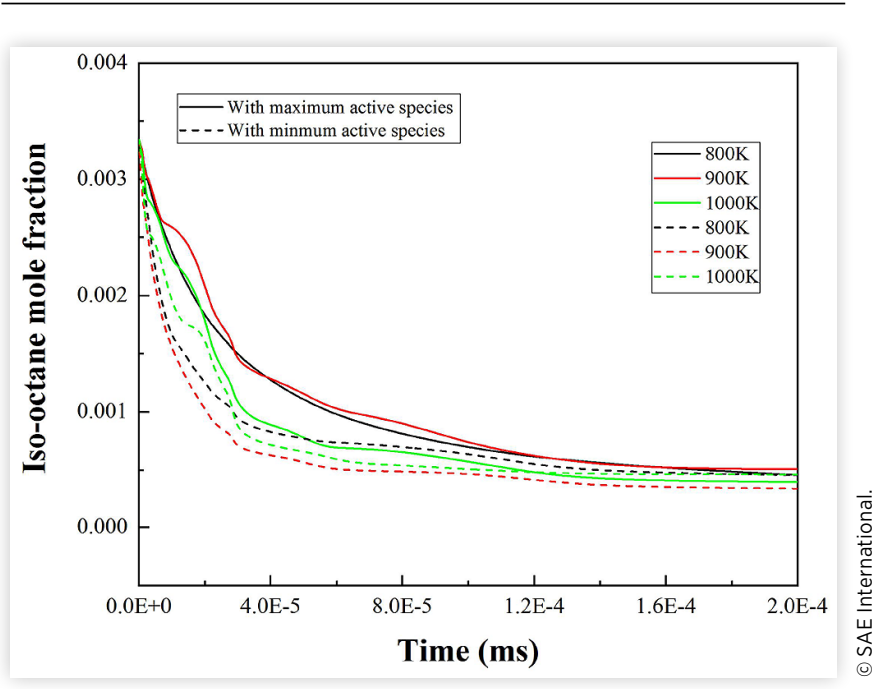

promoted for most cases with additional species from prechamber, and the highest peak heat release rate is obtained with eq $=3.0$ in the pre-chamber. However the heat release rate is reduced with the additional species from pre-chamber burning in an extremely rich condition. Concerning the minimum active species case shown in Figure 7, it predicts similar profiles but some differences in peak values. The initial heat release rates are suggested to be lower due to the less active species. The highest peak heat release rate is also obtained with eq $=3.0$ in pre-chamber, which is near 4 times of the peak value in figure 6 .

\section{Effects of Pre-Chamber Combustion Products on Laminar Flame Speed in Main Chamber}

While most investigations [19, 20] studied the laminar flame speed under the room temperature and atmospheric pressure, this study computed the laminar flame speed of an ultra-lean mixture at high temperature and pressure. The reliability of laminar flame speed computations is examined firstly. Figure $\underline{8}$ depicts the laminar flame speed of iso-octane for the equivalence ratio from 0.2 to 1.8 under the temperature of $900 \mathrm{~K}$ and pressure of 20 bar. From figure 8 , it presents a typical laminar flame speed variation tendency profile with respect to the equivalence ratio. The flame speed is increased from fuel lean to a stoichiometric condition and the peak value is obtained around the stoichiometric condition. After that, flame speed is reduced when burning a richer mixture. Therefore, the simulations results are reliable and it is found that the laminar flame speed of iso-octane under the equivalence ratio of 0.4 is $22.6 \mathrm{~cm} / \mathrm{s}$.

Figure 9 describes the laminar flame speed of the ultralean mixture in main chamber with additional species from
FIGURE 5 Ignition performance with the addition of individual species from pre-chamber regarding the situations of (a) maximum chemical effects and minimum chemical effects.
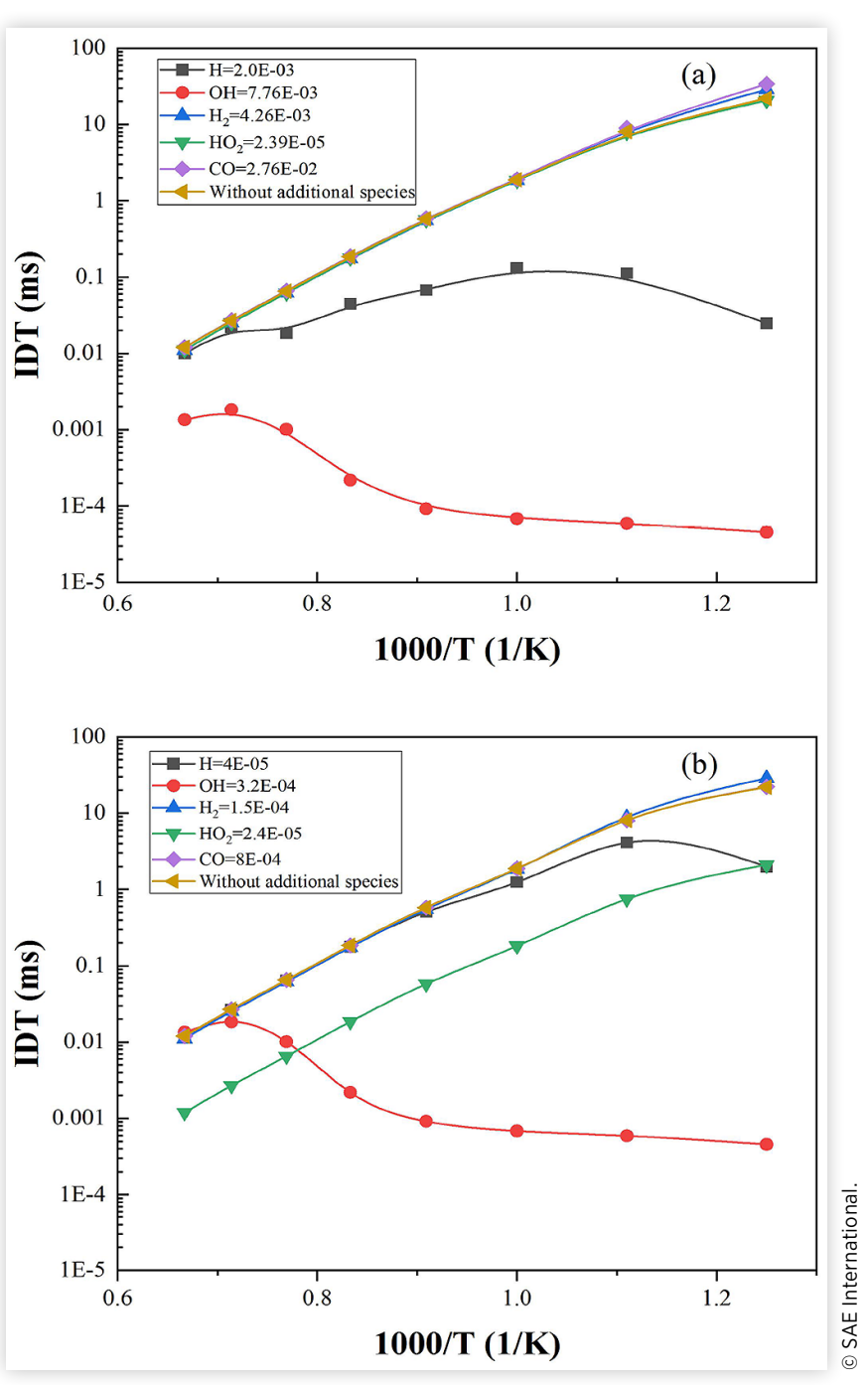

pre-chamber under a range of operating conditions for the maximum and minimum active species cases. The dash line is used as the baseline representing the laminar flame speed without additional species from pre-chamber. Comparing without and with additional species from pre-chamber, it is found that adding species from pre-chamber burning with a rich mixture improves the laminar flame speed of an ultralean mixture in the main chamber effectively. While with the addition of combustion species from pre-chamber burning in stoichiometric or ultra-rich conditions, the burning velocity is decreased slightly. Then looking into the two cases of combustion products with maximum and minimum active species, The peak values of laminar flame speed are obtained with eq $=2.0$ for maximum active species case and eq $=3.0$ for minimum active species case respectively. Comparing these two cases, it is also observed that minimum active species case generates higher laminar flame speed for all range of equivalence ratios. 
FIGURE 6 Heat release rate in main chamber with additional combustion products from pre-chamber for various equivalence ratios concerning combustion products with maximum active species.
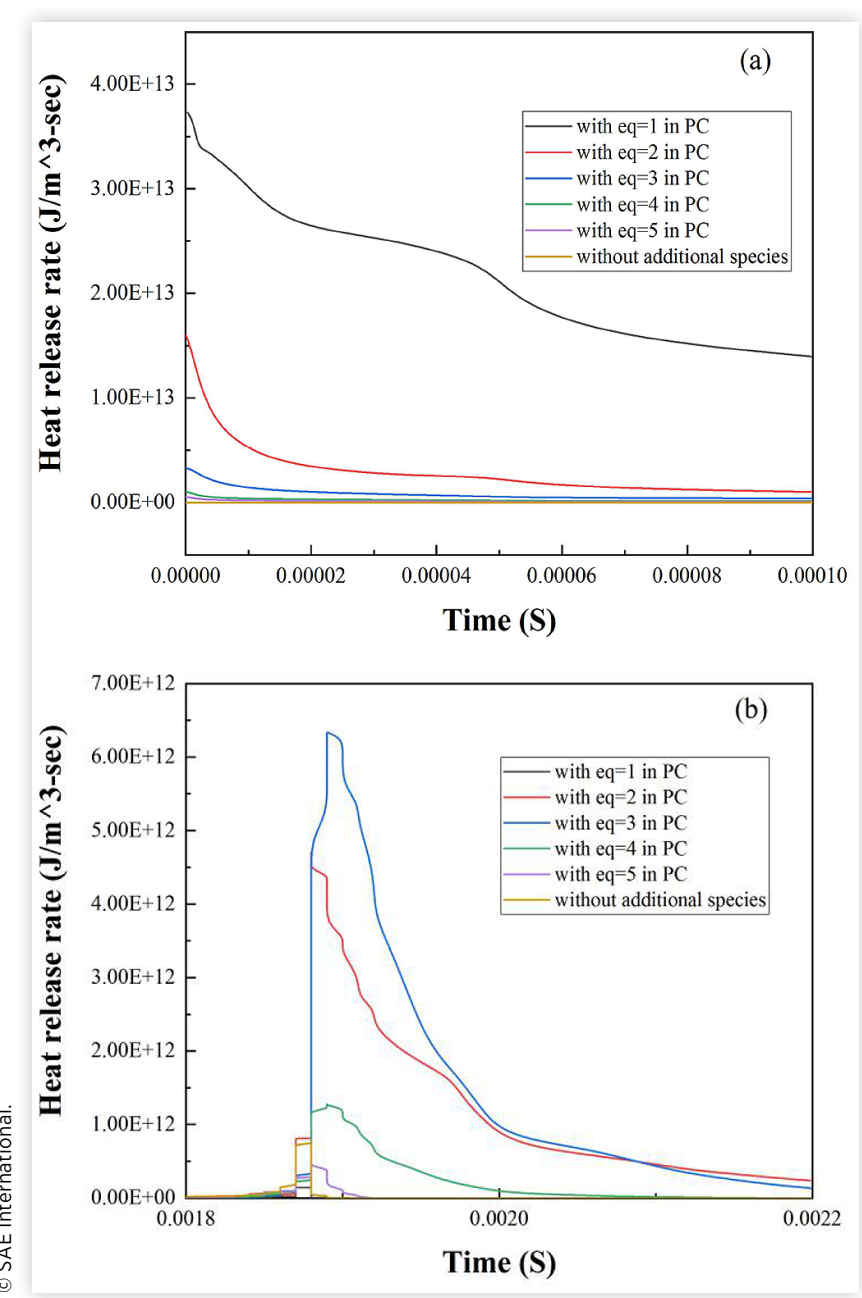

To further analyze chemical effects of pre-chamber combustion species on laminar flame speed of an ultra-lean mixture in main chamber, sensitivity analyses were performed showing high laminar flame speed, low laminar flame speed and without additional species cases. Figure 10 shows top ten reactions with high sensitivity coefficients for the without additional species case. From figure, we can found that active radical reactions show the highest sensitivity coefficients, which are then followed by low-carbon species reactions. Figure 11 displays the reactions with high sensitivities for high laminar flame speed cases. Figure 11(a) and (b) plot results of the highest laminar flame speed obtained with additional species from pre-chamber burning with eq $=2.0$ for the maximum active species case, and eq $=3.0$ for the minimum active species case respectively. From these figures, it is observed that high laminar flame cases basically share common reactions with high promoting and inhibiting sensitivities, but in sightly different orders. It is also worthy to note that the minimum active species case show an extremely high positive sensitivity coefficient over 0.8 for the reaction of $\mathrm{O}_{2}$ $+\mathrm{H}<=>\mathrm{O}+\mathrm{OH}$. Comparing to the without additional species
FIGURE 7 Heat release rate in main chamber with additional combustion products from pre-chamber for various equivalence ratios concerning combustion products with minimum active species.
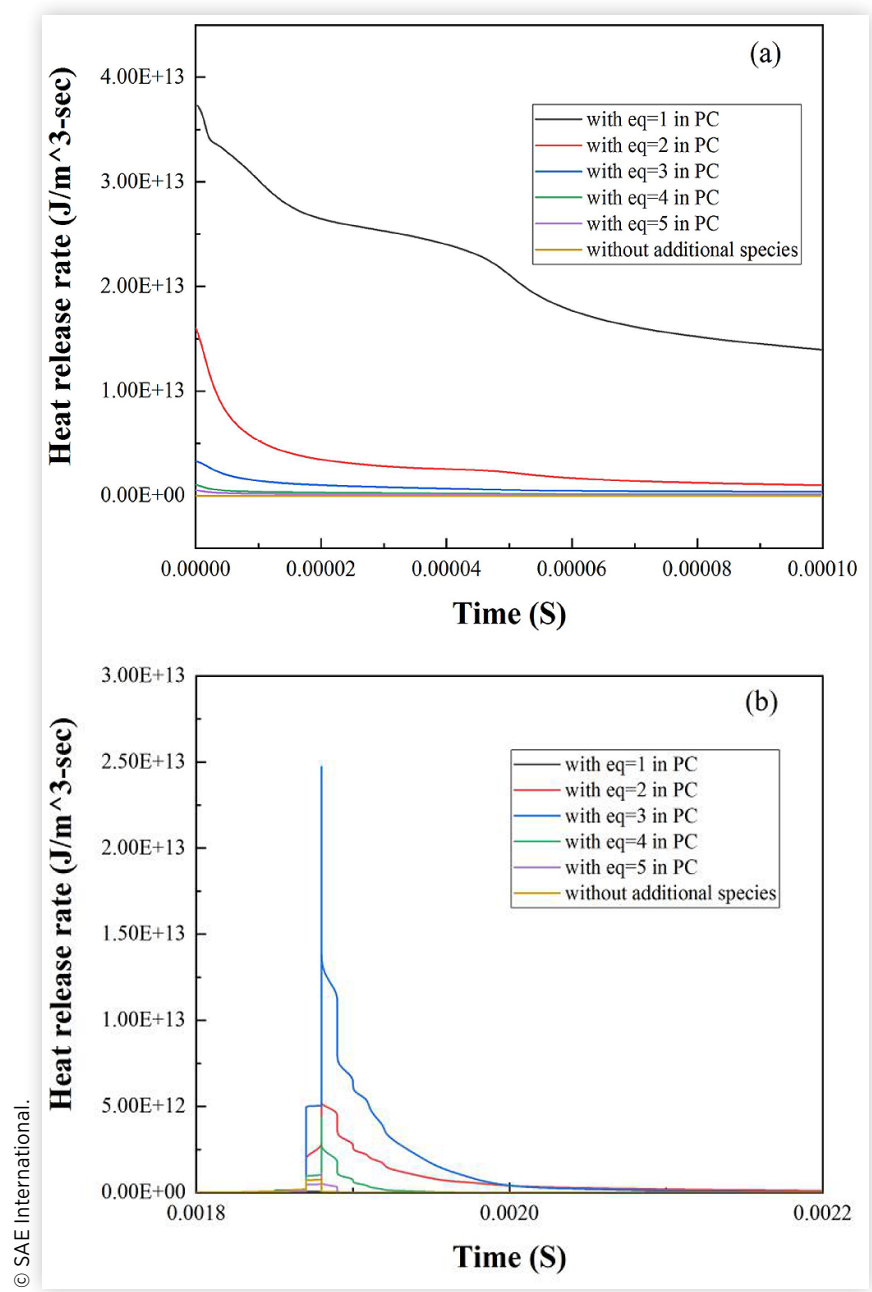

case, there are more radical reactions with higher sensitivities in high laminar flame speed cases, such as $\mathrm{HO}_{2}+\mathrm{H} \Leftrightarrow \mathrm{OH}$ $+\mathrm{OH}$ and $\mathrm{CH}_{3}+\mathrm{O} \Leftrightarrow \mathrm{CH}_{2} \mathrm{O}+\mathrm{H}$.

Figure 12 shows the sensitivity analyses of low laminar flame speed cases, which are found with the addition of combustion products from pre-chamber burning under the stoichiometric condition for both maximum and minimum active species cases. Similar to high laminar flame speed cases, low laminar flame speed cases also share similar reactions with high sensitivities. But the difference is that there are more low-carbon species reactions with higher sensitivity coefficients, such as $\mathrm{C}_{3} \mathrm{H}_{6}+\mathrm{H} \Leftrightarrow \mathrm{C}_{2} \mathrm{H}_{4}+\mathrm{CH}_{3}$ and $\mathrm{C}_{3} \mathrm{H}_{6}+\mathrm{OH} \Leftrightarrow$ $\mathrm{C}_{3} \mathrm{H}_{5}-\mathrm{A}+\mathrm{H}_{2} \mathrm{O}$.

Based on the above sensitivity analyses, we can conclude that important species in laminar flame speed computations include active radicals of $\mathrm{H}, \mathrm{OH}, \mathrm{O}, \mathrm{HO}_{2}$ and intermediate species of $\mathrm{CH}_{3}, \mathrm{CH}_{4}, \mathrm{C}_{2} \mathrm{H}_{4}, \mathrm{C}_{3} \mathrm{H}_{6}$ and $\mathrm{C}_{3} \mathrm{H}_{5}$-A. In the respect of the additional species from pre-chamber, it is found that the pre-chamber produces high concentrations of active radicals when burning with a stoichiometric mixture, but the main chamber generates a slower laminar flame speed with 
FIGURE 8 Laminar flame speed of iso-octane for a range of equivalence ratio under the temperature and pressure of $900 \mathrm{~K}$ and 20 bar.

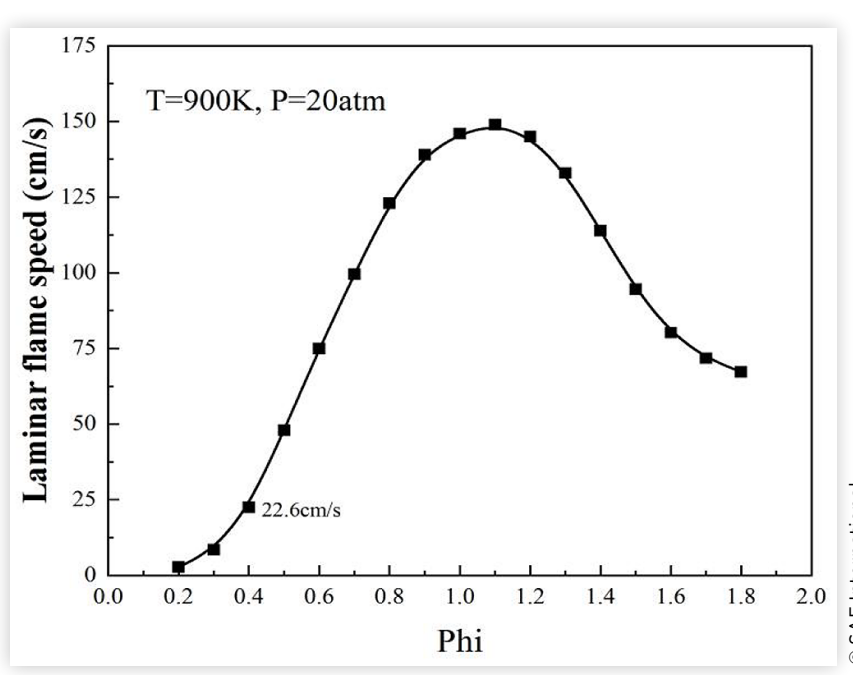

FIGURE 9 laminar flame speed in main chamber with additional species from pre-chamber regarding the maximum active species and with minimum active species cases. The dash line denotes the without additional species from prechamber.

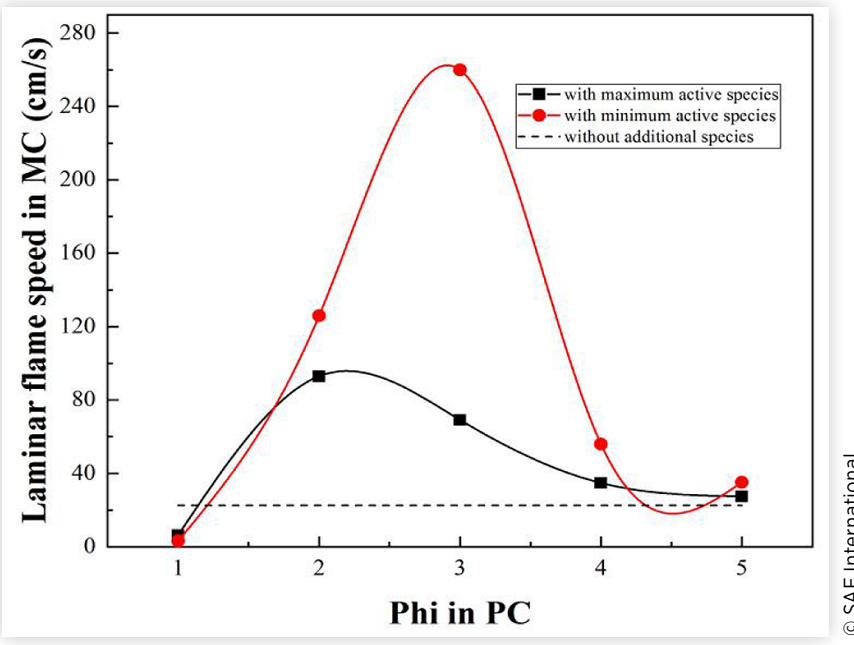

the addition of these species injected. While combustion products from pre-chamber burning with equivalence ratio of 2.0 or 3.0 do not show any advantages in the production of these species, but the laminar flame speed in the main chamber is significantly improved with these species added. Thus, there is no direct relationship suggested between these important species added from pre-chamber and main chamber laminar flame speed. Further studies about species sensitivity analysis need to be conducted since some intermediate reactions may potentially promote productions of these species during the combustion, which then influence the laminar flame speed.
FIGURE 10 Sensitivity analysis for laminar flame speed without additional species from pre-chamber.

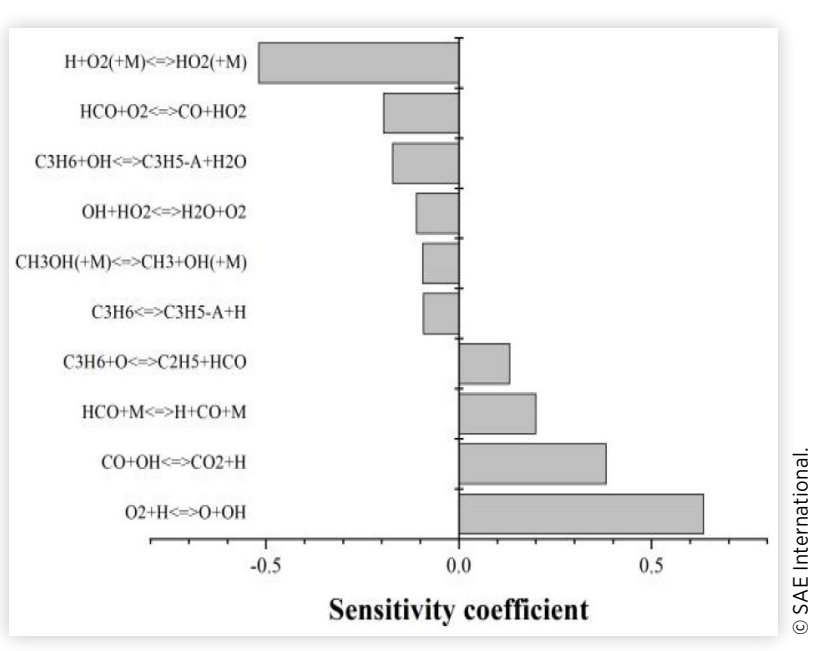

FIGURE 11 Sensitivity analysis for high laminar flame speed cases of (a) with eq $=2.0$ of maximum active species case from pre-chamber and (b) with eq $=3.0$ of minimum active species case from pre-chamber.

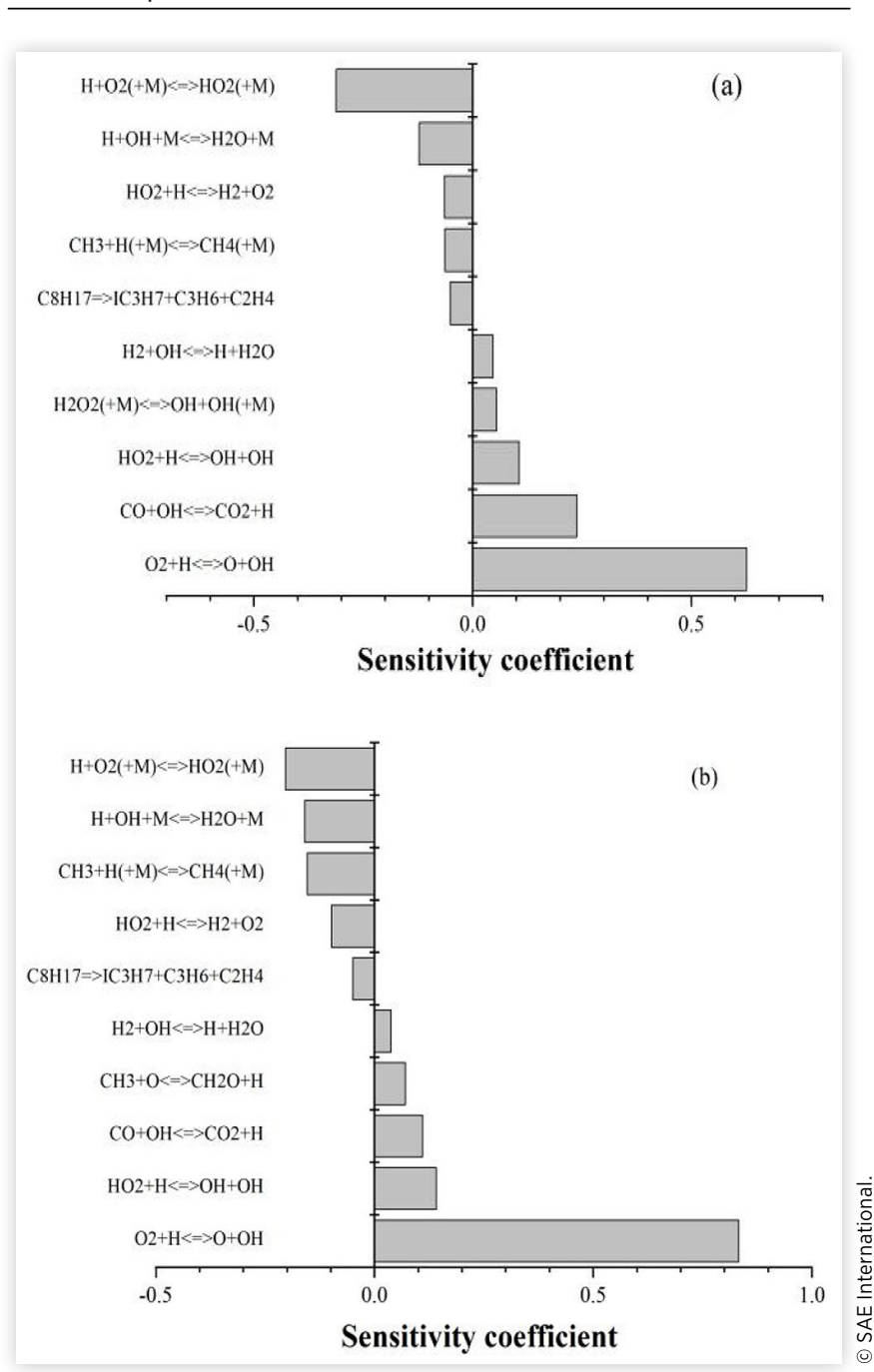


FIGURE 12 Sensitivity analysis for low laminar flame speed cases of (a) with eq 1.0 of maximum active species case from pre-chamber and (b) with eq $=1.0$ of minimum active species case from pre-chamber.

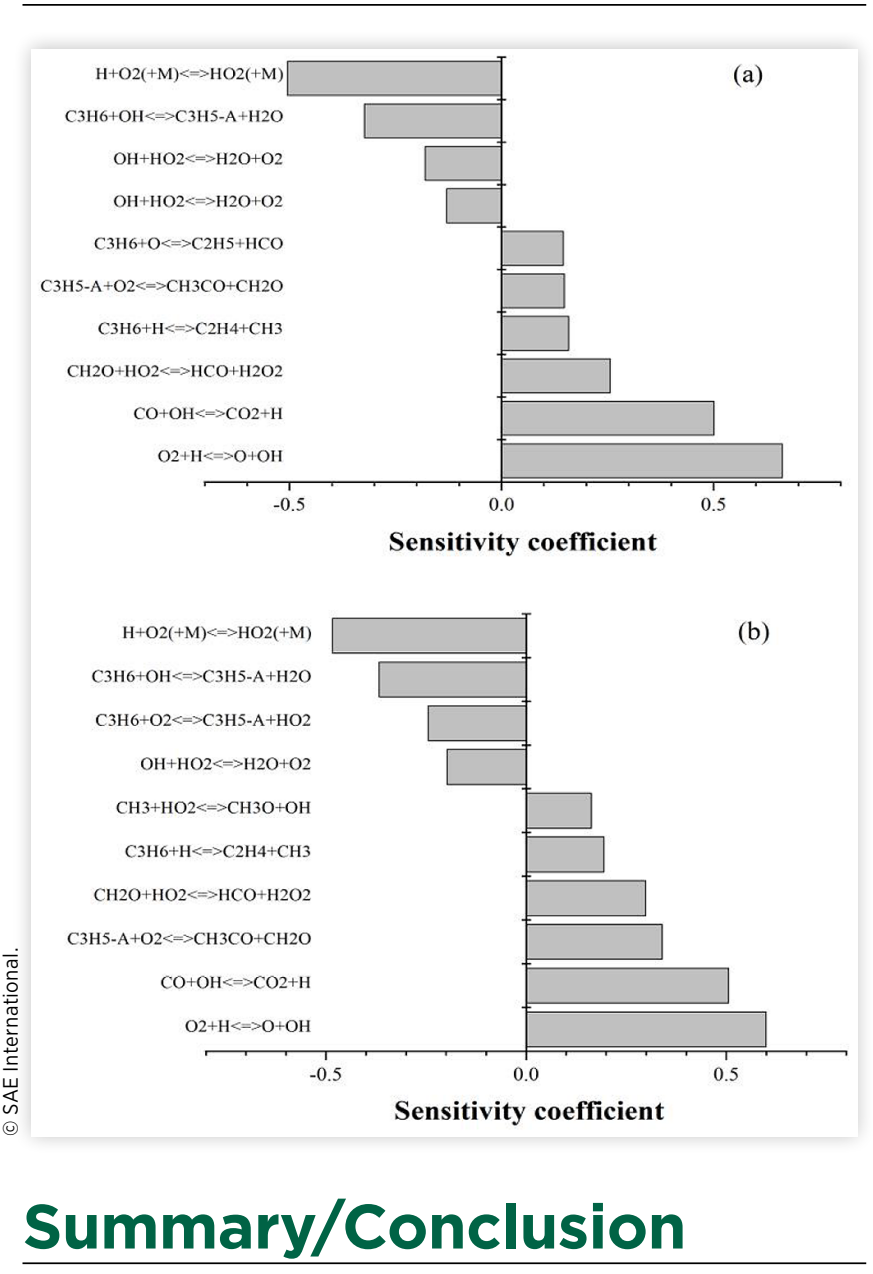

This paper studied the chemical effects of pre-chamber combustion products on the ignition performance of an ultralean mixture in the main chamber by developing a zerodimensional pre-chamber combustion model. The prechamber was simulated for a range of operating conditions and the main chamber was operated under the ultra-lean condition. Some important conclusions and finding are obtained by analyzing the main chamber combustion characteristics with additional species transported from prechamber regarding two cases of combustion products with maximum active species and with minimum active species.

1. For a range of equivalence ratios in pre-chamber, more active radicals are produced when burning with a stoichiometric mixture and more low carbon intermediate species are generated when burning a fuel rich mixture.

2. Ignition performance in the main chamber is significantly improved with the addition of combustion products from pre-chamber under the stoichiometric condition. This is mainly contributed to high concentrations of active radicals of $\mathrm{H}$ and $\mathrm{OH}$ injected from pre-chamber into main chamber, resulting in an ultra-quick radical-induced ignition behavior. While adding combustion products from pre-chamber burning with a richer mixture, there is no obvious changes.

3. Heat release rate in the main chamber is generally promoted by adding additional species from prechamber and the peak heat release rate value is obtained with combustion species from pre-chamber burning with the equivalence ratio of 3.0.

4. Laminar flame speed in the main chamber is enhanced by adding additional species from prechamber burning in relatively rich conditions, while adding species from pre-chamber in the stoichiometric or really rich conditions oppositely show some inhibiting effects in burning velocities.

\section{References}

1. Alvarez, C.E.C., Couto, G.E., Roso, V.R., Thiriet, A.B., and Valle, R.M., "A Review of Prechamber Ignition Systems as Lean Combustion Technology for SI Engines," Applied Thermal Engineering 128:107-120, 2018.

2. Kleeman, M.J. et al., "PM2. 5 Co-Benefits of Climate Change Legislation Part 2: California Governor's Executive Order S-3-05 Applied to the Transportationsector," Clim. Change 117(1-2):399-414, 2013.

3. Toulson, E., Watson, H., and Attard, W., “The Lean Limit and Emissions at Near-Idle for a Gasoline HAJI System with Alternative Pre-Chamber Fuels," SAE Technical Paper 200724-0120, 2007, https://doi.org/10.4271/2007-24-0120.

4. Attard, W., Toulson, E., Huisjen, A., Chen, X. et al., "Spark Ignition and Pre-Chamber Turbulent Jet Ignition Combustion Visualization," SAE Technical Paper 2012-01$\underline{0823}, 2012$, https://doi.org/10.4271/2012-01-0823.

5. Muller, M., Freeman, C., Zhao, P., and Ge, H., "Numerical Simulation of Ignition Mechanism in the Main Chamber of Turbulent Jet Ignition System," In ASME 2018 Internal Combustion Engine Division Fall Technical Conference, American Society of Mechanical Engineers Digital Collection, 2018.

6. Sakai, Y., Kunii, K., Tsutsumi, S., and Nakagawa, Y., "Combustion Characteristics of the Torch Ignited Engine," SAE Technical Paper 741167, 1974, https://doi. org/10.4271/741167.

7. Gentz, G., Thelen, B., Gholamisheeri, M., and Toulson, E., "A study of the Influence of Orifice Diameter on a Turbulent Jet Ignition System Through Combustion Visualization and Performance Characterization in a Rapid Compression Machine," Applied Thermal Engineering 81:399-411, 2015.

8. Wimmer, D., and Lee, R., "An Evaluation of the Performance and Emissions of a CFR Engine Equipped with a Prechamber," SAE Technical Paper 730474, 1973, https://doi. org/10.4271/730474.

9. Mehdiyev, R., and Wolanski, P., "Bi-Modal Combustion Chamber for a Stratified Charge Engine," SAE Technical Paper 2000-01-0196, 2000, https://doi.org/10.4271/200001-0196. 
10. Jarosinski, J., Lapucha, R., Mazurkiewicz, J., and Wojcicki, S., "Combustion System of a Lean-Burn Piston Engine with Catalytic Prechamber," SAE Technical Paper 2001-01-1186, 2001, https://doi.org/10.4271/2001-01-1186.

11. Gryglewski, W., "Influence of Rotation Rate on Combustion in Spark Ignition Engine," PhD diss., PhD Thesis, Lodz, Poland, 1995.

12. Muller, M., Freeman, C., Zhao, P., and Ge, H.. "Numerical Simulation of Ignition Mechanism in the Main Chamber of Turbulent Jet Ignition System," in ASME 2018 Internal Combustion Engine Division Fall Technical Conference, American Society of Mechanical Engineers Digital Collection, 2018.

13. Yousefi, A., and Birouk, M., "Numerical Study of the Performance and Emissions Characteristics of Natural Gas/ Diesel Dual-Fuel Engine using Direct And Indirect Injection Systems," in Proceedings of Combustion Institute-Canadian Section Spring Technical Meeting, University of Waterloo May, 10-12, 2016.

14. Attard, W.P., Blaxill, H., Anderson, E.K., and Litke, P., "Knock Limit Extension with a Gasoline Fueled PreChamber Jet Igniter in a Modern Vehicle Powertrain," SAE International Journal of Engines 5(3):1201-1215, 2012.

15. Atef, N., Kukkadapu, G., Mohamed, S.Y., Al Rashidi, M. et al., "A Comprehensive Iso-Octane Combustion Model with Improved Thermochemistry and Chemical Kinetics," Combustion and Flame 178:111-134, 2017.

16. Li, Y., Alfazazi, A., Mohan, B., Tingas, E.A. et al., "Development of a Reduced Four-Component (toluene/n-heptane/iso-octane/ethanol) Gasoline Surrogate Model," Fuel 247:164-178, 2019.

17. Campbell, C.S., and Egolfopoulos, F.N., "Kinetics Paths to Radical-Induced Ignition Of Methane/Air Mixtures," Combustion Science and Technology 177(12):2275-2298, 2005.

18. Liang, W., and Law, C.K., "On radical-Induced Ignition in Combustion Systems," Annual Review of Chemical and Biomolecular Engineering 10:199-217, 2019.
19. Yu, G., Law, C.K., and Wu, C.K., "Laminar Flame Speeds of hydrocarbon+ Air Mixtures with Hydrogen Addition," Combustion and Flame 63(3):339-347, 1986.

20. Egolfopoulos, F.N., Cho, P., and Law, C.K., "Laminar Flame Speeds of Methane-Air Mixtures under Reduced and Elevated Pressures," Combustion and Flame 76(34):375-391, 1989.

\section{Contact Information}

Wenxian Tang, Ph.D. student in Mechanical Engineering, Clean Combustion Research Centre (CCRC). KAUST, +966545754201, wenxian.tang@kaust.edu.sa.

\section{Acknowledgments}

This paper is based upon work supported by Saudi Aramco Research and Development Center FUELCOM3 program under Master Research Agreement Number 6600024505/01. FUELCOM (Fuel Combustion for Advanced Engines), is a collaborative research undertaking between Saudi Aramco and KAUST intended to address the fundamental aspects of hydrocarbon fuel combustion in engines, and develop fuel/ engine design tools suitable for advance combustion modes.

\section{Definitions/Abbreviations}

\author{
IDT - Ignition Delay Time \\ MFB - Mass Fraction Burned \\ PC - Pre-chamber \\ SI - Spark Ignition \\ TJI - Turbulent Jet Ignition
}

